\title{
Evaluation and Control of Mechanical Degradation of Austenitic Stainless 310S Steel Substrate During Coated Superconductor Processing
}

\author{
Seung-Gyu Kim ${ }^{1,4}\left(\mathbb{D} \cdot\right.$ Najung Kim² $\cdot$ Hyung-Seok Shim ${ }^{3} \cdot$ Oh Min Kwon ${ }^{1} \cdot$ Dongil Kwon ${ }^{1}$
}

Received: 13 October 2017 / Accepted: 22 November 2017 / Published online: 15 March 2018

(c) The Author(s) 2018

\begin{abstract}
The superconductor industry considers cold-rolled austenitic stainless 310S steel a less expensive substitute for Hastelloy $\mathrm{X}$ as a substrate for coated superconductor. However, the mechanical properties of cold-rolled $310 \mathrm{~S}$ substrate degrade significantly in the superconductor deposition process. To overcome this, we applied hot rolling at $900{ }^{\circ} \mathrm{C}$ (or $1000{ }^{\circ} \mathrm{C}$ ) to the $310 \mathrm{~S}$ substrate. To check the property changes, a simulated annealing condition equivalent to that used in manufacturing was determined and applied. The effects of the hot rolling on the substrate were evaluated by analyzing its physical properties and texture.
\end{abstract}

Keywords Coated superconductor $\cdot$ Mechanical degradation $\cdot$ Substrate $\cdot$ Austenitic stainless 310 S steel $\cdot$ Rolling temperature

\section{Introduction}

In the hope of reducing the cost of superconductor materials, the superconductor industry is now considering stainless steel substrates as a substitute for Hastelloy, a more expensive Ni alloy [1-3]. The mechanical properties of the substrate strongly influence those of the coated superconductor. When the superconducting layer in a coated superconductor starts to yield, its superconductivity is greatly reduced by the current-shielding effect [4-6]. Austenitic stainless 310S steel was chosen by the manufacturer as a substrate material, but its mechanical strength decreased rapidly after exposure to high temperature during production. The production process

Seung-Gyu Kim

manwater88@snu.ac.kr

1 Department of Materials Science and Engineering, Seoul National University, Seoul 08826, Republic of Korea

2 Samsung Electronics Co., Ltd, Yongin 17113, Republic of Korea

3 Division of Industrial Metrology, Korea Research Institute of Standards and Science, Daejeon 305-340, Republic of Korea

4 Center of Advanced Innovation Technologies, VSB Technical University of Ostrava, 70800 Ostrava, Czech Republic for coated superconductors has four steps: (1) preparation of substrate, (2) formation of lattice matching and buffer layer, (3) deposition of superconducting layer, (4) formation of protection layer. The details are shown in Fig. 1a. Figure 1b shows that the substrate is exposed to temperatures up to $850{ }^{\circ} \mathrm{C}$ during the process.

\section{Experimental Details}

Four intermediate coated superconductors (raw substrate/ after electro-polishing/after heat treatment/after Ag-sputtering) were acquired from a manufacturer's actual processing. Coated superconductors using both $310 \mathrm{~S}$ steel and Hastelloy $\mathrm{X}$ were provided. Each specimen has the form of a 10-mmwide tape and was processed into a standard tensile specimen for tensile testing [7]. A micro-tensile tester (Instron, ElectroPuls e3000) was used and the extension rate of tensile test was $3 \mathrm{~mm} / \mathrm{min}$. Tensile testing was done in the longitudinal direction.

In order to evaluate the effect of rolling, conditions replacing the actual production process are required. Raw substrates were exposed to the conditions in Table 1, and tensile testing and microstructure analysis were done. Samples were exposed to high temperatures in a tube furnace (JVAC) and then furnace-cooled, as in the actual processing. 


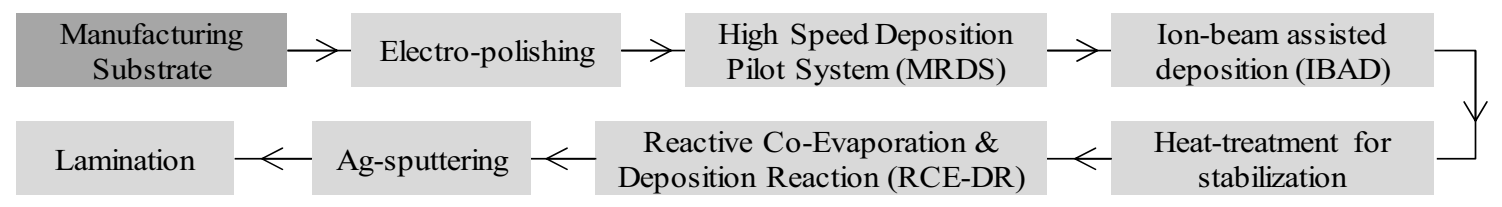

(a)

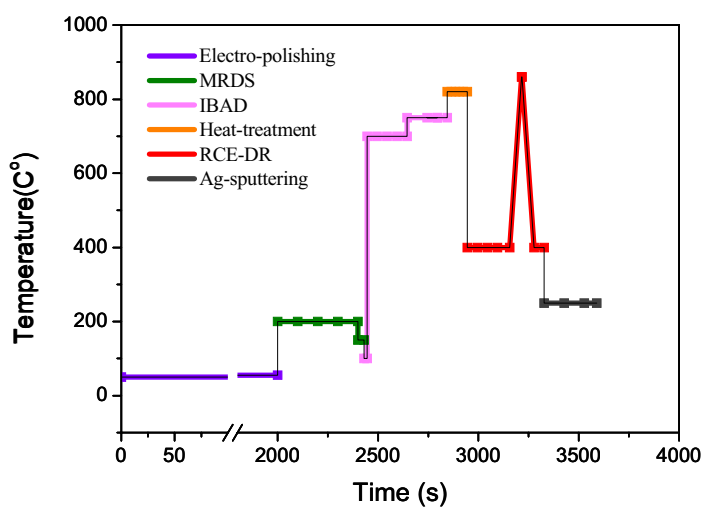

(b)

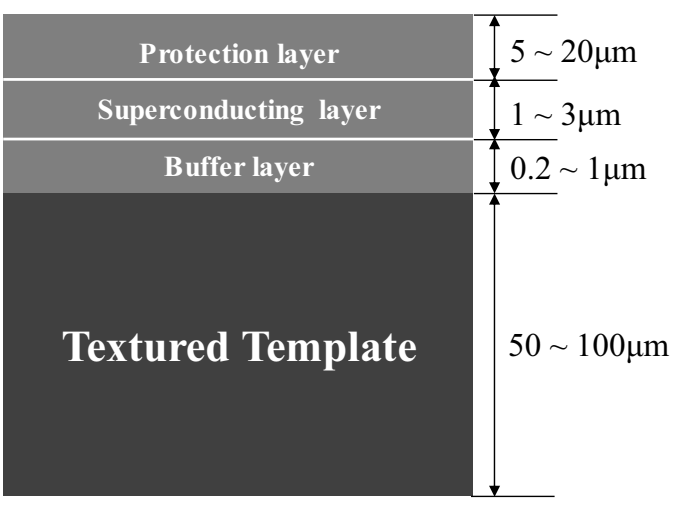

(c)

Fig. 1 Manufacture of the coated superconductor: a process sequence, $\mathbf{b}$ temperature profile, $\mathbf{c}$ structure of finished product

Table 1 Annealing conditions of raw substrate for comparison with finished coated superconductor

\begin{tabular}{ll}
\hline Parameter & Value \\
\hline Temperature $\left({ }^{\circ} \mathrm{C}\right)$ & $780 / 820 / 860$ \\
Annealing time $(\min )$ & $20 / 30 / 50 / 70 / 80 / 90$ \\
\hline
\end{tabular}

The mechanical properties and microstructure of the finished coated conductor were compared with those of the substrates exposed to the given conditions. For microstructure analysis by EBSD (TSL), the specimen surfaces were processed sequentially using abrasive paper (\#2000) and diamond suspension ( 3 and $1 \mu \mathrm{m})$ to eliminate surface roughness. Ion milling was performed for $10 \mathrm{~min}$ at $6 \mathrm{kV}$ acceleration.

An austenitic $310 \mathrm{~S}$ stainless steel plate of chemical composition $\mathrm{Fe}-24.8 \mathrm{Cr}-19.2 \mathrm{Ni}-1.2 \mathrm{Mn}-0.05 \mathrm{C}$ (wt\%) was used to make substrates under various rolling conditions. The $10-\mathrm{mm}$-thick plate was annealed at $1100{ }^{\circ} \mathrm{C}$ for $30 \mathrm{~min}$, and hot-rolling and cold-rolling were applied to produce a $0.3 \mathrm{~mm}$-plate. To investigate the influence of rolling temperature and the variation with annealing, raw substrates were fabricated with three different rolling temperatures, details are summarized in Table 2. After rolling, mechanical and micro-structural analysis is done. Tensile testing is done in the rolling direction.
Table 2 Rolling and annealing conditions for $310 \mathrm{~S}$ steel samples to control mechanical degradation

\begin{tabular}{lllll}
\hline No. & $\begin{array}{l}\text { 1st rolling method } \\
(10 \mathrm{~mm} \rightarrow 1 \mathrm{~mm})\end{array}$ & $\begin{array}{l}\text { 2nd rolling method } \\
(1 \mathrm{~mm} \rightarrow 0.3 \mathrm{~mm})\end{array}$ & Annealing condition & Reduction (\%) \\
\hline R1 & Cold rolling & Cold rolling & Not annealed & 97 \\
R2 & Hot rolling $\left(900^{\circ} \mathrm{C}\right)$ & Cold rolling & Not annealed & 97 \\
R3 & Hot rolling $\left(1000^{\circ} \mathrm{C}\right)$ & Cold rolling & Not annealed & 97 \\
A1 & Cold rolling & Cold rolling & $820^{\circ} \mathrm{C} / 70 \mathrm{~min}$ & 97 \\
A2 & Hot rolling $\left(900^{\circ} \mathrm{C}\right)$ & Cold rolling & $820^{\circ} \mathrm{C} / 70 \mathrm{~min}$ & 97 \\
A3 & Hot rolling $\left(1000^{\circ} \mathrm{C}\right)$ & Cold rolling & $820^{\circ} \mathrm{C} / 70 \mathrm{~min}$ & 97 \\
\hline
\end{tabular}




\section{Results and Discussion}

\subsection{Strength Change After Different Processing Step}

The mechanical properties of the coated superconductor with Hastelloy X substrate were not notably degraded as processing progressed. The yield strength of the substrate after processing was reduced by about $20 \%$ in Fig. 2b. On the other hand, the coated superconductor on the $310 \mathrm{~S}$ steel substrate showed remarkable mechanical property degradation after processing: the yield strength was reduced by about $70 \%$ in Fig. 1 a.

Coated superconductor substrates rolled at high reduction rates are exposed to high-temperature environments when the superconducting layer is deposited. Three microstructures develop when $310 \mathrm{~S}$ steel is reduced by rolling: a twin and matrix (T-M) lamellar structure, fine-grained structure, and twins-not-developed structure. Only cold rolling is applied to the $310 \mathrm{~S}$ steel substrates in these experiments. (The rolling process for the Hastelloy X substrate is not known.) In this study, the substrate goes through very severe deformation process. After rolling with high reduction ratio, most microstructures are covered by very dense T-M lamellar structure. Hence, 310 S steel can be expected to exhibit, like other ferrous metals, rapid microstructural changes such as recovery, recrystallization and grain growth in high-temperature environments [8-11]. The Hastelloy X substrate must also be subjected to severe plastic deformation by cold rolling. Nevertheless, it is expected that some production difference lessens any decrease in mechanical properties.

As mentioned above, substrates were annealed to determine conditions equivalent to the actual production process. Eighteen annealed substrates were prepared according to the experimental conditions in Table 1. The temperatures were measured near the maximum temperature in the actual production process. Five properties of the finished coated superconductor and the 18 annealed substrates are compared: yield strength, tensile strength, elongation, ratio of recrystallized grains (grain orientation spread $<1^{\circ}$ ), and ratio of annealed twins (misorientation angle $>60^{\circ}$ ). According to Clickner, the superconducting layer on the substrate affects the total strength by about $10 \%$ or less [5]. Considering this, we used some margin in comparing yield strength and tensile strength. The condition ' $820^{\circ} \mathrm{C} / 70 \mathrm{~min}$ ' was most similar. As shown in Table 3, all five comparisons are almost identical.

\subsection{Effect of Rolling Conditions}

Figure 3 shows tensile test results for the substrates in Table 2. Before annealing, the results for the three substrates are very similar: they have high strength and very low elongation in Fig. 3a. But the results after annealing are not at all similar: the tensile properties of A1 (made by cold-rolling only) are greatly reduced, but values for the hot-rolled substrates (A2 and A3) are reduced less. In particular, the reduction in substrate $\mathrm{A} 2$ is the least.
Fig. 2 Tape-type tensile test results: a austenitic stainless 310S steel substrate, b Hastelloy X substrate at different processing steps

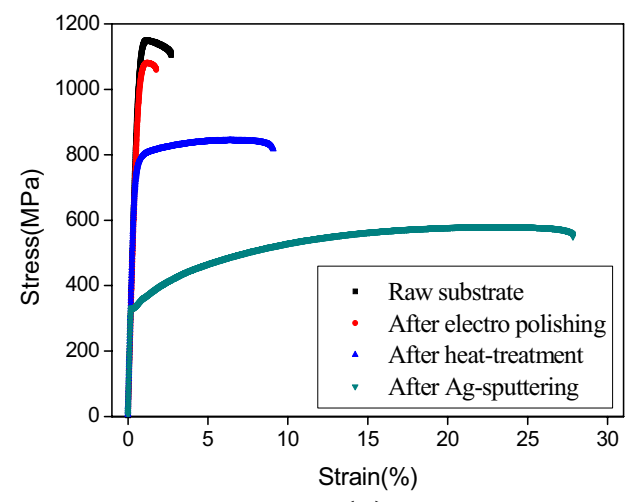

(a)

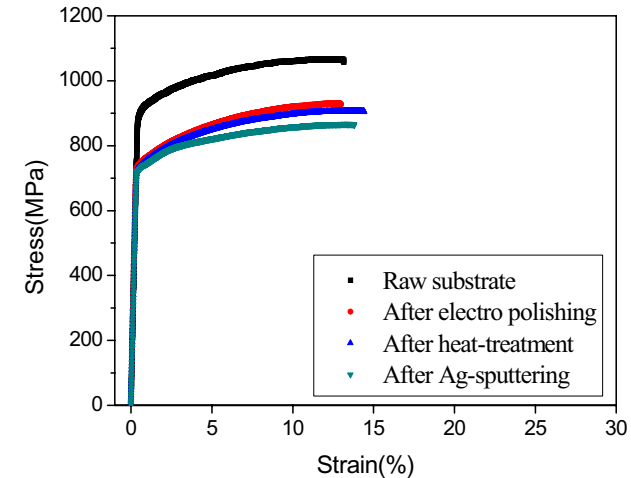

(b)
Table 3 Comparison of results: equivalent condition $\left(820^{\circ} \mathrm{C} / 70 \mathrm{~min}\right)$ and completed coated superconductor

\begin{tabular}{llllll}
\hline Case & $\begin{array}{l}\text { Yield } \\
\text { strength } \\
(\mathrm{MPa})\end{array}$ & $\begin{array}{l}\text { Tensile } \\
\text { strength } \\
(\mathrm{MPa})\end{array}$ & Elongation (\%) & $\begin{array}{l}\text { Ratio of recrystal- } \\
\text { lized grains (\%) }\end{array}$ & $\begin{array}{l}\text { Ratio of } \\
\text { annealed } \\
\text { twins (\%) }\end{array}$ \\
\hline $\begin{array}{c}\text { Equivalent condition } \\
\left(820^{\circ} \mathrm{C} / 70 \text { min }\right)\end{array}$ & 306.6 & 558.5 & 22.4 & 29 & 17 \\
$\begin{array}{c}\text { Completed coated } \\
\text { superconductor }\end{array}$ & 296.4 & 511.9 & 22.4 & 29 & 19 \\
\hline
\end{tabular}


Fig. 3 Tensile test results for substrates according to rolling condition: a before annealing, $\mathbf{b}$ after annealing

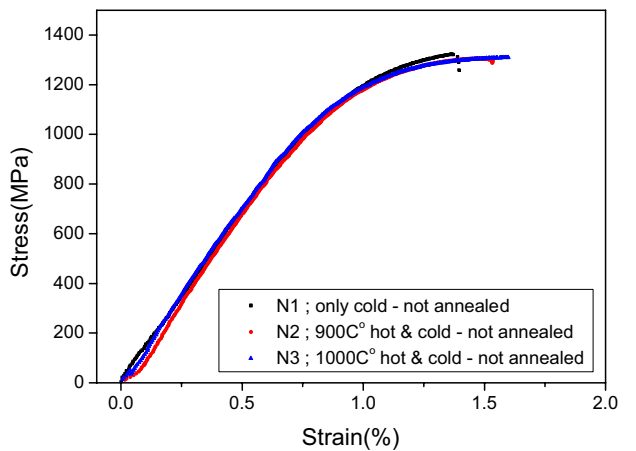

(a)

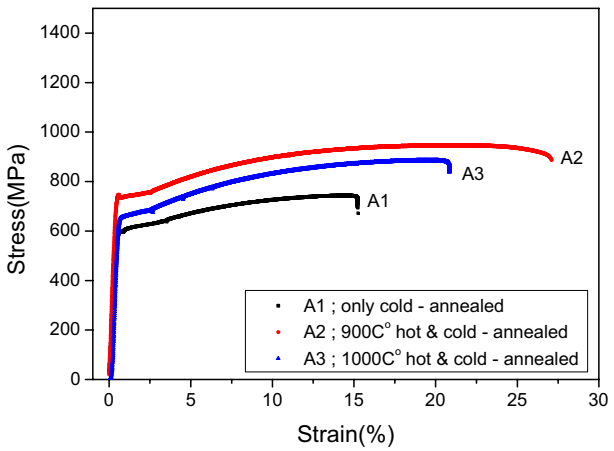

(b)
Microstructural analysis was performed to determine the reason for the difference in mechanical properties after annealing. The difference between cold rolling and hot rolling was confirmed by the recrystallization ratio. Recrystallization of about $45 \%$ was achieved for the A1 substrate, whereas only $29 \%$ was recrystallized in $\mathrm{A} 2\left(900^{\circ} \mathrm{C}\right.$ hot and cold rolled/annealed) and $\mathrm{A} 3\left(1000^{\circ} \mathrm{C}\right.$ hot and cold rolled/ annealed) in Fig. 4. It can be seen that the previous hot rolling worked significantly to reduce the recrystallization ratio.

Figure $5 \mathrm{a}, \mathrm{b}$ shows the microstructure when hot rolling is done only before cold rolling. Figure $5 \mathrm{~b}$ clearly confirms that dynamic recrystallization occurs with hot rolling at $1000^{\circ} \mathrm{C}$ $[12,13]$, but it is relatively difficult to confirm the dynamic recrystallization texture of specimens hot-rolled at $900^{\circ} \mathrm{C}$. In the specimen cold-rolled to only $1 \mathrm{~mm}$, the recrystallization structure was not observed with EBSD because the strain in the microstructure was too great. The specimen rolled to $0.3 \mathrm{~mm}$ with cold-rolling shows severe plastic deformation and sub-grain boundaries. The more deformed the substrates are, the smaller the grain size becomes. So, after rolling to $0.3 \mathrm{~mm}$, the microstructure could not be observed with EBSD because of the extensive strain. Instead, the hot-rolled specimens (A2 and A3) in Fig. 5b show very similar microstructures, with similar low-angle-boundary ratios. The difference in mechanical properties after annealing is caused by the difference in position of the sub-grain boundaries formed in cold rolling [14]. Specimen A2 forms sub-grain boundaries inside the small grains produced by hot rolling, while A3 forms large grains by dynamic recrystallization during hot rolling. When cold rolling is applied to the interiors of large grains, they are divided into small grains by sub-grain boundaries. Generally, sub-grain boundaries have low angles and low energy [15], so that they cause less strengthening (Hall-Petch strengthening) than grain boundaries [16, 17]. It can be seen that the specimens subjected to hot rolling at $1000{ }^{\circ} \mathrm{C}$ have larger grain size. The difference between

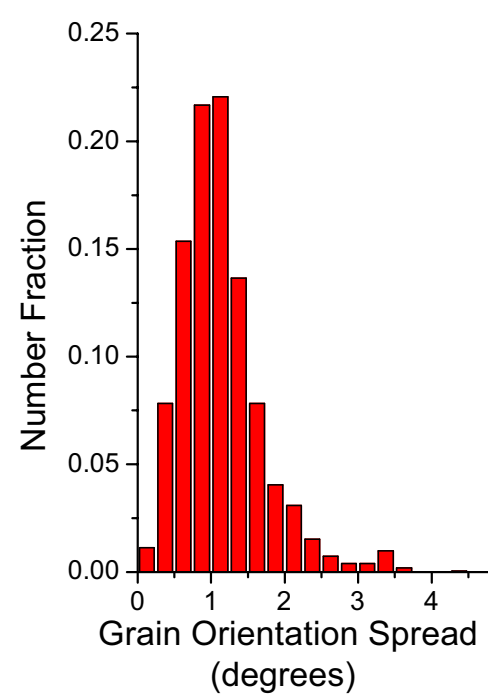

(a)

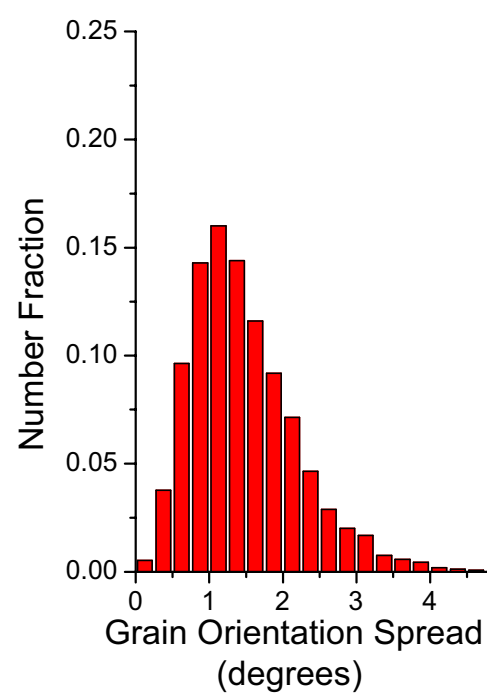

(b)

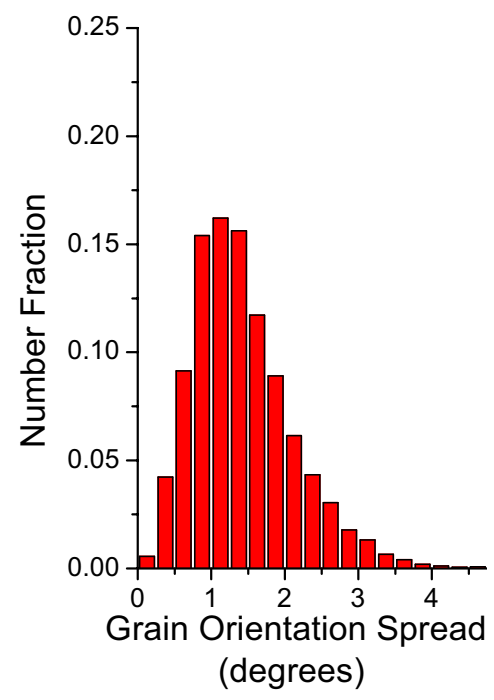

(c)

Fig. 4 Recrystallized grain ratio in substrate after annealing: a A1: cold rolling only—annealed, b A2: $900{ }^{\circ} \mathrm{C}$ hot rolling and cold rollingannealed, c A3: $1000{ }^{\circ} \mathrm{C}$ hot rolling and cold rolling-annealed 

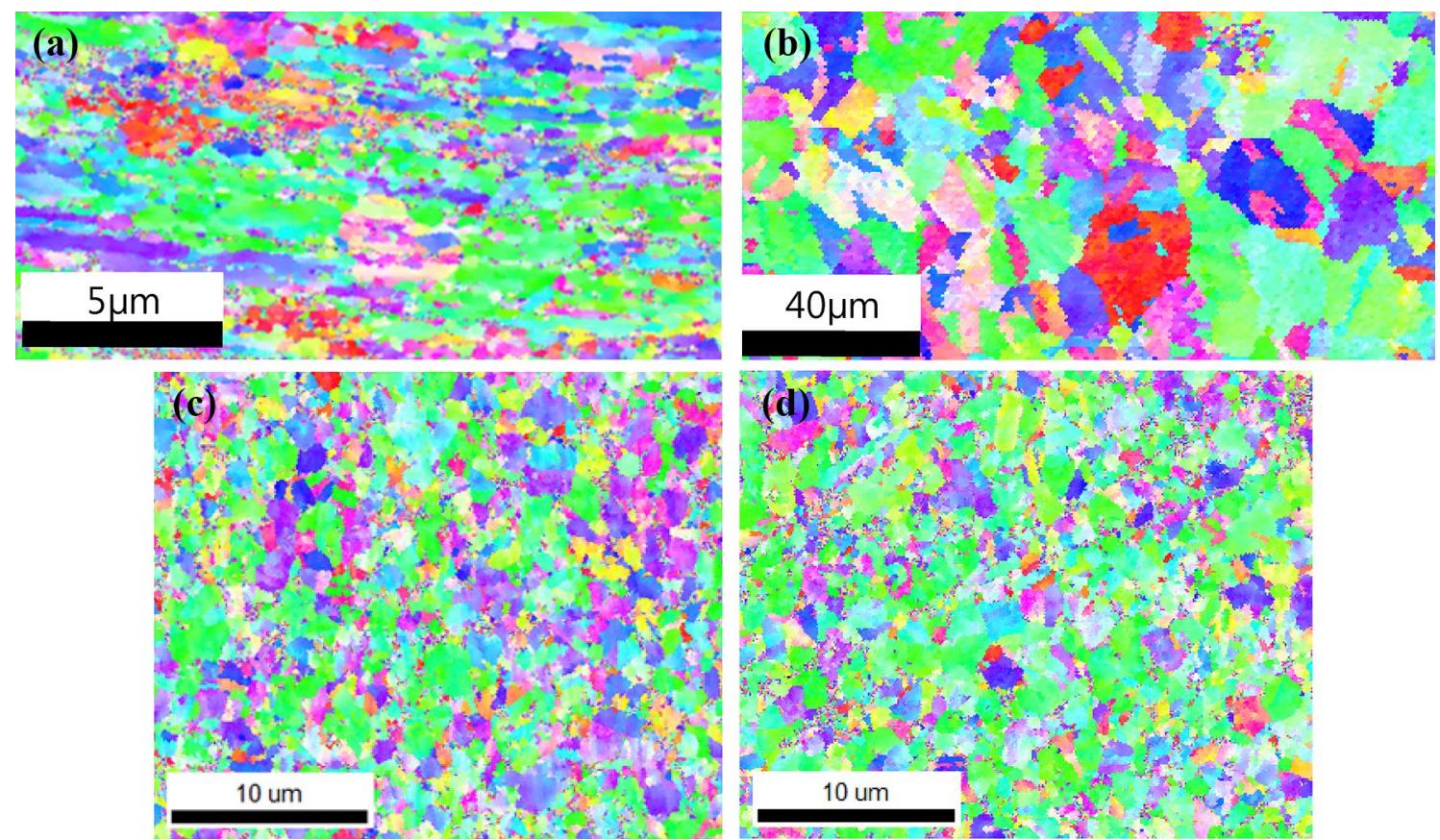

Fig. 5 Microstructures a after $900{ }^{\circ} \mathrm{C}$ hot rolling, b after $1000^{\circ} \mathrm{C}$ hot rolling, c A2, d A3 using EBSD

samples A2 and A3 is that grain boundaries, which are relatively resistant to dislocation penetration, have a greater strengthening effect than weak sub-grain boundaries.

As another point, the hardening level of non-recrystallized particles is expected to differ between samples A2 and A3. In order to investigate this, inverse pole figures (IPF) were analyzed. According to Kamaya et al. [18], when greater plastic deformation is applied to the grain interior, IPF points tend to spread. This phenomenon can be understood as a change in orientation to retain continuity between grains under deformation. It can be seen in Fig. 6 that more strain is present in the non-recrystallized grains in substrate A2 than in substrate A3 [9, 19-21]. The difference is apparent in ND and RD in Fig. 6. In ND, A3 shows many grains arrange close to the [101]. The grains of A2 are concentrated not only on [101] but also on [112]. The difference can be found in RD: the grains in A3 are concentrated at [111], while the grains in $\mathrm{A} 2$ are continuously distributed between [111] and [001].

\section{Conclusion}

These results show the effects of dynamic recovery and recrystallization with hot rolling before cold rolling and can be explained by two phenomena. First, there was little dynamic recrystallization in $\mathrm{A} 2\left(900{ }^{\circ} \mathrm{C}\right.$ hot and cold rolled/annealed) and significantly more at $\mathrm{A} 3\left(1000^{\circ} \mathrm{C}\right.$ hot and cold rolled/ annealed). Hot-rolling at $1000{ }^{\circ} \mathrm{C}$ causes significant grain recrystallization and coarsening. After cold rolling, A2 and A3 become similar in microstructure, including the sub-grain boundaries. But these substrates differ in the distribution of sub-grain boundaries and grain boundaries generated by hot rolling. At the grain boundaries, the substrate hot-rolled at $1000{ }^{\circ} \mathrm{C}$ has larger grains than that hot-rolled at $900{ }^{\circ} \mathrm{C}$, as can be inferred from Fig. 5a, b. Sub-grain boundaries have less strengthening effect (Hall-Petch strengthening) than grain boundaries because they are easier for dislocations to penetrate. Hence the two specimens show a gap in mechanical properties. 

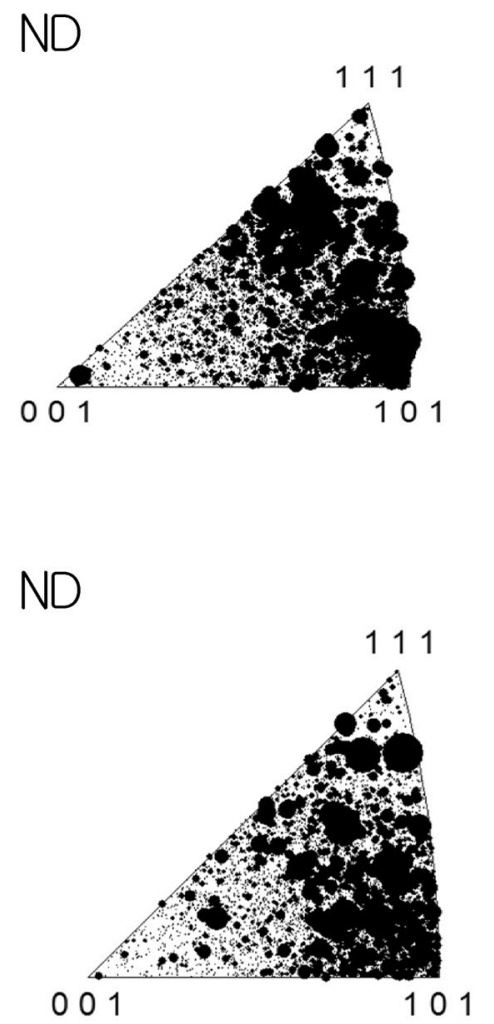

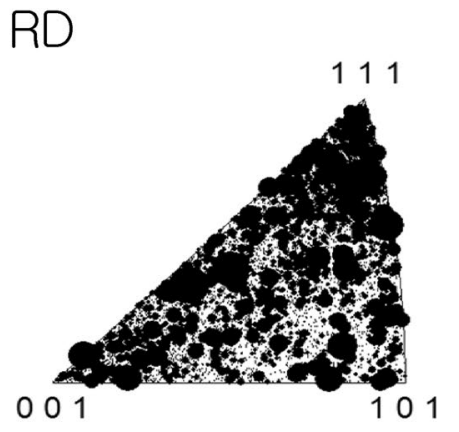

(a)

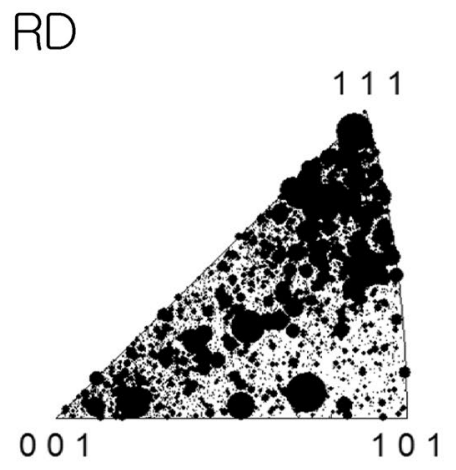

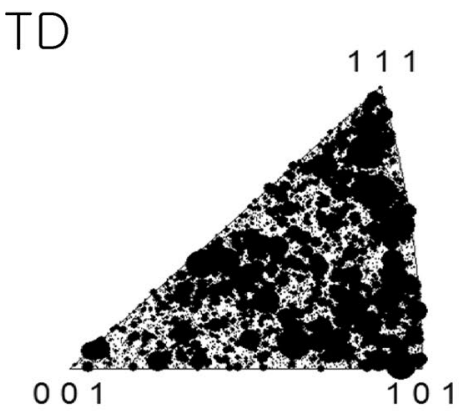

TD

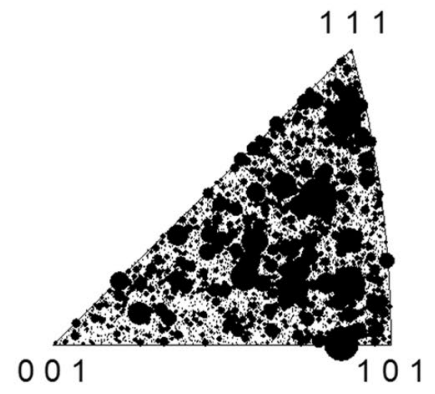

(b)

Fig. 6 Inverse pole figures (IPF) of crystal orientation: a A2: $900{ }^{\circ} \mathrm{C}$ hot rolling and cold rolling —annealed, b A3: $1000{ }^{\circ} \mathrm{C}$ hot rolling and cold rolling—annealed

Second, the amount of strain energy stored by rolling is different. The distinction is not large, but clearly a specimen hot-rolled at $900^{\circ} \mathrm{C}$ has more stored strain energy than one hot-rolled at $1000^{\circ} \mathrm{C}$. Further experiments are needed to know why the recovery of substrate hot-rolled at $1000^{\circ} \mathrm{C}$ differs from that of the substrate hot-rolled at $900{ }^{\circ} \mathrm{C}$.

The work described above confirmed that the mechanical properties of the finished coated superconductor can be improved by using hot rolling during production of the substrate.

Acknowledgements This work was supported by the National Research Foundation of Korea (NRF) grant funded by the Ministry of Science, ICT \& Future Planning (MSIP) (No. NRF-2015R1A5A1037627).

Open Access This article is distributed under the terms of the Creative Commons Attribution 4.0 International License (http://creativecommons.org/licenses/by/4.0/), which permits unrestricted use, distribution, and reproduction in any medium, provided you give appropriate credit to the original author(s) and the source, provide a link to the Creative Commons license, and indicate if changes were made.

\section{References}

1. E.D. Specht, A. Goyal, D.F. Lee, F.A. List, D.M. Kroeger, M. Paranthaman, R.K. Williams, D.K. Christen, Supercond. Sci. Technol. 11, 10 (1998)

2. A.E. Vorobieva, I.M. Abdyukhanov, D.N. Rakov, V.V. Samusevich, A.V. Nikolaev, A.V. Borisov, YuN Belotelova, V.A. Drobyshev, M.M. Potapenko, L.M. Kryukova, J. Phys. Conf. Ser. 507, 2 (2014)

3. L.H. Zheng, J.X. Jin, Y.G. Guo, J.G. Zhu, Nat. Sci. 1, 33-41 (2006)

4. N. Cheggour, J.W. Ekin, C.C. Clickner, R. Feenstra, P. Goyal, D.F. Paranthaman, D.F. Lee, D.M. Kroeger, D.K. Christen, Adv. Cryog. Eng. 48, 461-468 (2002)

5. C.C. Clickner, J.W. Ekin, N. Cheggour, C.L.H. Thieme, Y. Qiao, Y.-Y. Xie, A. Goyal, Cryogenics 46, 432-438 (2006)

6. B. ten Haken, H.H.J. ten Kate, J. ten Brink, I.E.E.E. Trans, Appl. Supercond. 5, 1298-1301 (1995)

7. ASTM, ASTM E8: Standard Test Methods for Tension Testing of Metallic Materials (ASTM Int, West Conshohocken, 2002)

8. T. Leffers, D. Juul Jensen, Textures Microstruct. 14-18, 933-952 (1991)

9. F.J. Humphrey, M. Hatherly, Recrystallization and Related Annealing Phenomena, 2nd edn. (Elsevier, Oxford, 2004), pp. 70-75

10. T. Morikawa, K. Higashida, J. Mater. Sci. 41, 2581-2585 (2006) 
11. T. Morikawa, K. Higashida, Mater. Trans. 41, 620-624 (2010)

12. L.G. Martinez, K. Imakuma, A.F. Padilha, Steel Res. Int. 63, 221-223 (1992)

13. S.I. Kim, Y.C. Yoo, Mater. Sci. Eng. A 311, 108-113 (2001)

14. R. Sedlacek, W. Blum, J. Kratochvil, S. Forest, Metall. Mater. Trans. A 32, 1-9 (2001)

15. G.E. Lloyd, A.B. Farmer, D. Mainprice, Tectonophysics 279, 55-78 (1997)

16. K. Lu, L. Lu, S. Suresh, Science 324, 349-352 (2009)
17. G.E. Dieter, Mechanical metallurgy, SI Metric edn. (McGraw-Hill Inc., London, 1988), pp. 189-191

18. M. Kamaya, A.J. Wilkinson, J.M. Titchmarsh, Nucl. Eng. Des. 235, 713-725 (2005)

19. J.G. Lenard, M. Pietrsyk, L. Cser, Mathematical and Physical Simulation of the Properties of Hot Rolled Products (Elsevier, New York, 1999), pp. 61-85

20. H.J. McQueen, D.L. Bourell, J. Met. 39, 28-35 (1987)

21. E.I. Poliak, J.J. Jonas, Acta Mater. 44, 127-136 (1996) 